\title{
磁歪式トルクセンサにおけるシェイキング磁界重畳の効果
}

\section{Effect of Superposition of a Shaking Field in a Magnetostrictive Type Torque Sensor}

\author{
上野新太郎・小松大祐・児塔典沙・脇若弘之 \\ 信州大学, 長野市若里 4-17-1 ( ₹ 380-8553)
}

\author{
S. Ueno, D. Komatsu, T. Koto, and H. Wakiwaka \\ Shinshu University, 4-17-1 Wakasato, Nagano-shi, 380-8553, Nagano, J apan
}

There are many requirements for measuring torque, such as non-contact with the shaft, small size of the measurement device, and simple installation. Other requirements include no special processing in the shaft and cost-effectiveness. Therefore, we have proposed a magnetostrictive-type torque sensor for a steering shaft using an inverse magnetostrictive effect.

Generally, a magnetostrictive-type torque sensor for a low-carbon steel shaft has a large hysteresis to the torque and output fluctuation due to axis rotation. With this sensor, we have shown that the hysteresis on the output voltage can be drastically decreased, if the magnetic shaking method is applied.

Key words: magnetostrictive-type torque sensor, hysteresis, torque-sensitive, magnetic shaking

\section{1.はじめに}

トルクの情報は, 種々の機械あるいは電気機械系の高度な制御 に必要とされ, 構造か簡単で非接触式のトルクセンサは強く望ま れている1)。特に, 産業機器の分野において, トルクを検出し, 制 御することは, 省工ネ化や高機能化を可能にする . また , 軸の劣 化や過負荷をセンサの出力電圧から知ることができるため, 保守 の面でも大きな効果力期待できる .

トルクセンサの中でも本論文で述べる磁歪式トルクセンサ (MagnetostrictivetypeTorqueSensor: 以下,MTS と略記) は, 軸に接触しないで簡単にセンサを装着し , トルクを検出すること ができるので, 多くの機器に安価でセンサを導入することが可能 である、また, 軸には特別な加工が必要でないため, 軸の強度を 高くすることができ , MTS における許容印加トルクは,ひずみゲ 一ジ式 , 位相差式のトルクセンサよりも大きい .

しかし , MTSには, トルクに対するヒステリシスが大きい, 軸 の回転に伴う出力電圧の変動が大きい, 温度依存性が大きい, 外 部磁界や時間経過により軸の磁化状態力変化するなど問題点も多 (12),3).

このトルク (応力) に対するヒステリシスを低減するため, シ ヤフトに流す励振磁界を大きくする方法が一般に取られているが， この方法では高厉振周波数の場合, 電力損失が大きく, 発熱の恐 れがあり適用に関して制限を受(ナる2) 4) . 他にも , 直交シェイキ ング法と呼ばれる, 振幅の比較的大きな交流磁界 (シェイキング 磁界) を励振磁界と直交方向に加えることによって磁壁を連続的 に振動させ , 磁壁のピンニング力を実効的に低减させる方法 4) 6) や, トルク (応力) 值を測定する直前にシャフトを脱磁する事に よって, 磁壁のピンニング力や出力電圧の変動を低減させる方法 などがある 6) 8) .

そこで本論文は, トルクに対するヒステリシスを低减するため
に, 厉振磁界に異なる周波数の交流磁界を重畳する, 磁気シェイ キング法の適用を提案し検討を行った . 同手法はヒステリシスの 低減に大きな効果があり，同時にトルク感度力増加する効果もあ ることを示し, シェイキンク磁界の周波数への依存性についても 検討したため報告する . 以下に本論文の内容について示した .

(1) 磁丕式トルクセンサの基本構成と動作原理

(2) シェイキング条件によるトルク感度の増加とヒステリシス低 減効果

\section{2. 磁歪式トルクセンサの基本構成と動作原理}

\section{1 MSの動作原理}

Fig. 1 にMTS の概観図を示した . MTS はリング状の2極構造 であり, 円周方向の磁気異方性の検出を行う . シャフト円周方向 にAＤの4つの検出コアがあり，弚れ光れの検出コアに検出コ イルを巻きつけてある . 励振コイルは , シャフトを囲むよう巻き つナることで,励振コイルの個体差を考慮する必要かなく,常に， 軸の円周方向に均一な磁界を生じさせることが可能である . 無卜 ルク時は, 全ての検出コアに流れる磁束の量は等しい . トルクが 加わると, シャフト表面 $\pm 45^{\circ}$ 方向に応力差力栍じ, 逆磁歪効果 の影響より, 磁化容易軸と磁化困難䡛力現れる。これにより, 検 出コア A と B ,およびC とDに流れる磁束の量に差力生じて , こ れらの差をとることでトルクに比例した誘起電圧か検出コイルか ら検出される MTS とシャフト間のギャップ $\mathrm{g}$ は $0.5 \mathrm{~mm}$ である . 式(1)に検出電圧 VDとトルク $T$ の関係式を示した .

$$
V_{\mathrm{D}}=a_{\mu}\left(\mu_{1}-\mu_{2}\right)=a_{\sigma}\left(\sigma_{1}-\sigma_{2}\right)=a_{\mathrm{T}} T \quad[\mathrm{~V}]
$$

ここに, $a_{\mu}$ : 比透磁率差に対する感度 $[\mathrm{V} / \mathrm{Pa}], \mu_{1}, \mu_{2}$ : シャ フト長手 $\pm 45^{\circ}$ 方向の比透磁率 , $a_{\sigma}$ : 主応力差に対する感度 [V / $\mathrm{Pa}$, $\sigma_{1}, \sigma_{2}$ : シャフト長手 $\pm 45^{\circ}$ 方向の応力 $[\mathrm{Pa}], a_{\mathrm{T}}$ : トルク 感度 $[\mathrm{V} /(\mathrm{N} \cdot \mathrm{m})]$

Flow of

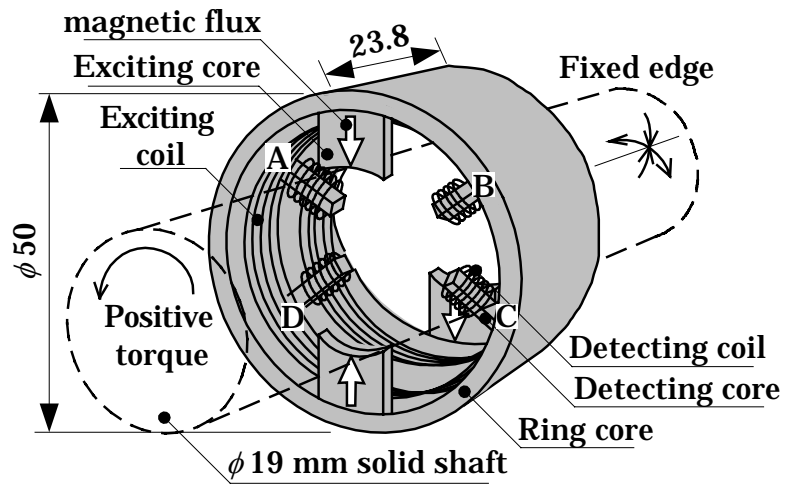

Fig. 1 Appearance of theMTS (unit: $\mathrm{mm}$ ). 


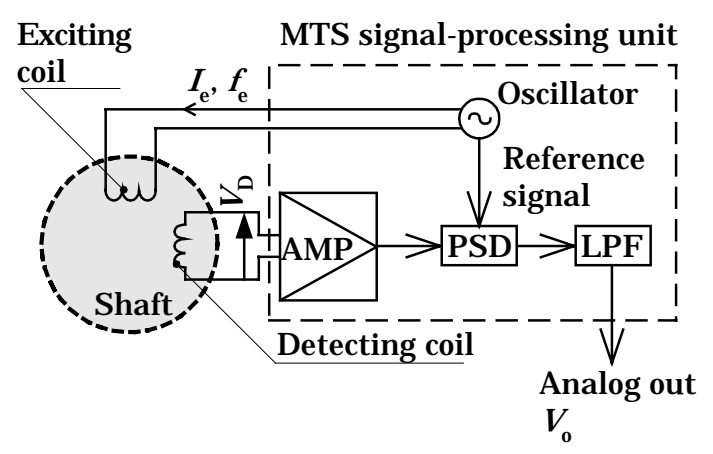

Fig. 2 Block diagram of thetorque measurement system.

Table 1 Spedifications of coils in the MTS.

\begin{tabular}{l|l|l}
\hline Items & Number of turns & Diameter of wire \\
\hline Exciting coil & 250 turns $\times 2$ coils & $\varphi 0.2 \mathrm{~mm}$ \\
\hline Detecting coil & 400 turns $\times 4$ coils & $\varphi 0.1 \mathrm{~mm}$ \\
\hline
\end{tabular}

Table 2 Composition of S25C (unit : \%).

\begin{tabular}{c|c|c|c|c|c}
\hline Items & $\mathrm{C}$ & $\mathrm{Si}$ & $\mathrm{Mn}$ & $\mathrm{P}$ & $\mathrm{S}$ \\
\hline $\mathrm{S} 25 \mathrm{C}$ & 0.22 & 0.15 & 0.30 & $\sim 0.03$ & $\sim 0.035$ \\
& $\sim 0.28$ & $\sim 0.35$ & $\sim 0.60$ & & \\
\hline
\end{tabular}

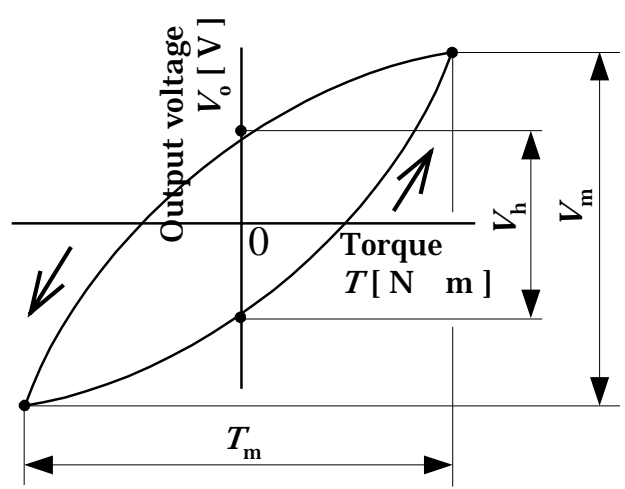

Fig. 3 Concept chart of the output voltageto thetorque

\section{2 信号処理回路のブロック图}

MTS の検出コイルは , トルクに比例した誘起電圧力検出できる ように接続され，乥の誘起電圧は信号処理回路へ入力される.Fig.2 にトルク測定システムのブロック図を示した.検出電圧 Vいは増幅 器を通り，位相検波回路て同期整流される。光の後，ローパスフ イルタを通過し, 出力電圧 $V_{0}$ となる.正トルクは+の直流電圧, 負トルクはーの直流電圧に変換される .

\section{3 測定環境}

Table1に,MTS におけるコイルの仕樣を示した . また ,Table 2に,シャフトの組成を示した.測定対象となるシャフトは,機械 構造用炭素鋼剛材 S 25 C である.S25C に $5 \mathrm{kA} / \mathrm{m}$ の磁界を加えた ときの保磁力は $0.3 \mathrm{kA} / \mathrm{m}$ であり，残留磁束密度は $0.87 \mathrm{~T}$ ，また飽 和磁束密度は $1.61 \mathrm{~T}$ である。

\section{4 トルク感度とヒステリシスの定義}

Fig. 3に , トルクに対する出力電圧の概念図を示した .トルクと

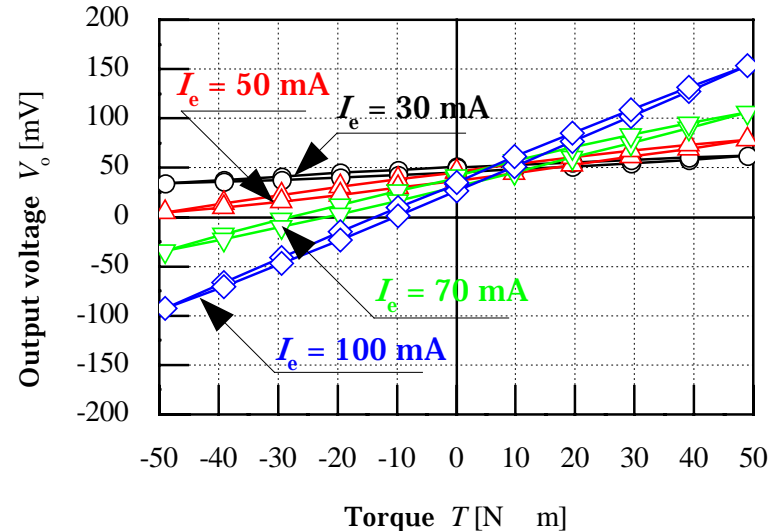

Fig. 4 Output voltage characteristics vs. thetorquein MTS. ( $f_{\mathrm{e}}=1 \mathrm{kHz}, g=0.5 \mathrm{~mm}, \mathrm{~S} 25 \mathrm{C}$ shaft $)$

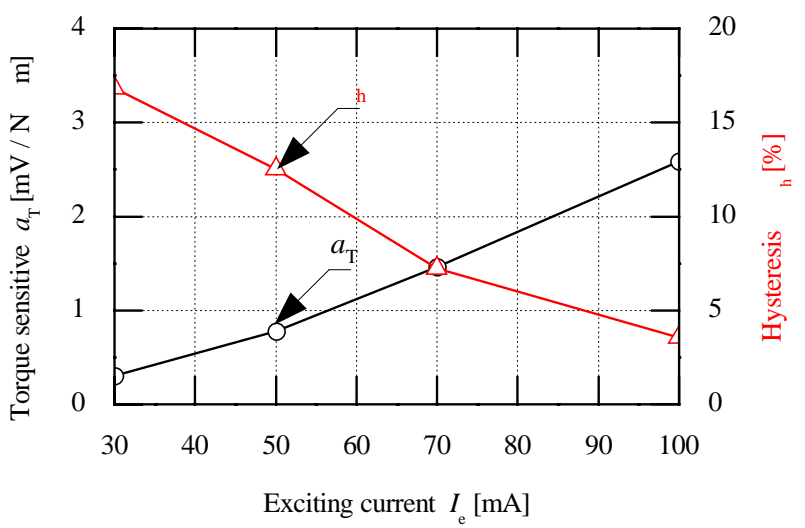

Fig. 5 Torquesensitiveand hysteresis characteristics vs. the exaiting aurrent. ( $f_{\mathrm{e}}=1 \mathrm{kHz}, g=0.5 \mathrm{~mm}, \mathrm{~S} 25 \mathrm{C}$ shaft $)$

シャフト表面 4 45 方向の比透磁率の間にヒステリシスカ存在 するため，MTSの出力電圧にも大きなヒステリシスを持つ．

ここで, 最大トルク $49 \mathrm{~N} \cdot \mathrm{m}$ を加えた時のトルク感度 $a_{\mathrm{T}}$ とヒ ステリシス $\epsilon_{\mathrm{h}}$ を，以下の式(2),(3)のように定義した .

$$
\begin{array}{ll}
a_{T}=\frac{V_{m}}{T_{m}} & {[\mathrm{~V} /(\mathrm{N} \cdot \mathrm{m})]} \\
\varepsilon_{h}=\frac{V_{h}}{V_{m}} \times 100 & {[\%]}
\end{array}
$$

ここに $V_{\mathrm{m}}$ : 最大トルクを加えた時の出力電圧差 $[\mathrm{V}], V_{\mathrm{h}}$ : 同一 トルクて最大出力電圧差 $[\mathrm{V}], T_{\mathrm{m}}$ : 最大卜ルク $(=98 \mathrm{~N} \cdot \mathrm{m})[\mathrm{N} \cdot$ $\mathrm{m}]$

\section{MSのトルク出力特性}

Fig. 4 に, MTS によるトルクに対する出力電圧特性を示した . 正トルクと負トルクの出力電王に対称性があり, シャフトの逆磁 丕効果を直接利用できていることか確忍できた。

Fig. 5 に, 励振電流に対するトルク感度特性, ヒステリシス特性 を示した . 励振電流 $I_{\mathrm{e}}$ の増加に伴いトルク感度は上昇 , ヒステリ シスは低減した . ここで, 励振電流 $I_{\mathrm{e}}=30 \mathrm{~mA}$ の時トルク感度 $a_{\mathrm{T}}$ は $0.3 \mathrm{mV} / \mathrm{N} \cdot \mathrm{m}$ となった .一方, ヒステリシス $\epsilon_{\mathrm{h}}$ は $18 \%$ とな つた .乥こで,ヒステリシスが $18 \% と$ 比較的大きい $I_{\mathrm{e}}=30 \mathrm{~mA}$ を 励振条件と設定して，これに励振磁界とは異なる周波数の交流磁 界を重畳する，磁気シェイキング法の効果を以下て述べる。 
Signal-processing unit of magnetic shaking method

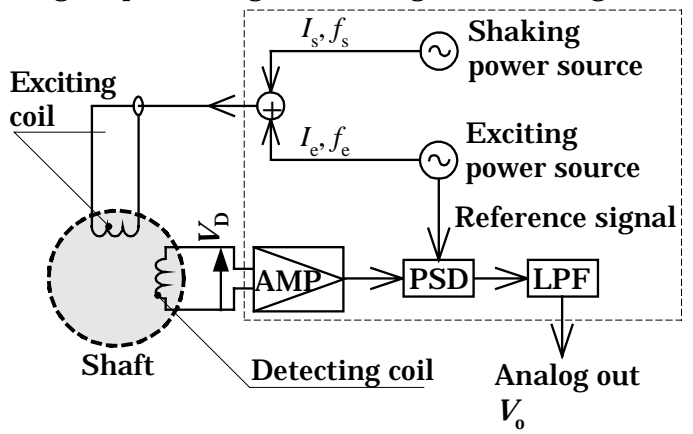

Fig. 6 Block diagram of thetorque measurement system in the magnetic shaking method.

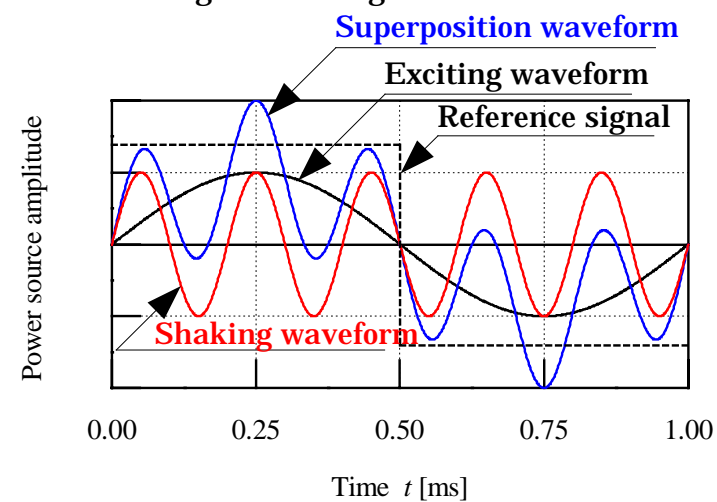

Fig. 7 Superposition waveform of the exciting power source and shaking $\left(f_{\mathrm{e}}=1 \mathrm{kHz}, f_{\mathrm{s}}=5 \mathrm{kHz}\right)$.

4. シェイキング磁界を重畳した時のトルク出力特性

\section{1 磁気シェイキング法の概念}

センサにおいて , ヒステリシスの低減は重要である . 強磁性体 に応力か作用した場合, 磁化は応力方向に対して, 磁壁の移動と 磁化の回転力起きる.しかし，測定対象内の空孔，夾杂倠物などに より, 磁壁がピン止めされ, 全ての磁壁の移動と磁化の回転力起 きるわけではない，つまり，磁壁のピンニング力が大きいと，磁 壁の不可逆的移動によりヒステリシスを生じる．

磁気シェイキング法は, 厉振磁界とは異なる周波数の交流磁界 を重畳させ , 磁壁を連続的に振動させることで, 磁壁のピンニン グ力を低减させる方法である .

Fig. 6 に 磁気シェイキング法におけるトルク測定システムのブ ロック図を示し ,Fig. 7 に,励振用波形とシェイキング用波形の重 畳波形の一例を示した . 直接的に , 励振コイルに励振磁界とは異 なる周波数のシェイキンク磁界を重胃させ , 位相検波回路で励振 磁界に起因した出力電圧成分のみ同期整流させ検出する .ここで， 本論文の磁気シェイキング法は, 直交シェイキング法 5) 7) と異な り，励振磁界の方向にシェイキンク磁界を重畳させるだけで良く， 特別な構造を必要としない。

励振用波形とシェイキング用波形の入力電圧の関係式を，以下 の式(4), (5)に示した .

$$
\begin{array}{ll}
v_{\mathrm{e}}=V_{\mathrm{e}} \sin \left(2 \pi f_{\mathrm{e}}\right) t & {[\mathrm{~V}]} \\
v_{\mathrm{s}}=V_{\mathrm{s}} \sin \left(2 \pi f_{\mathrm{s}}\right) t & {[\mathrm{~V}]}
\end{array}
$$

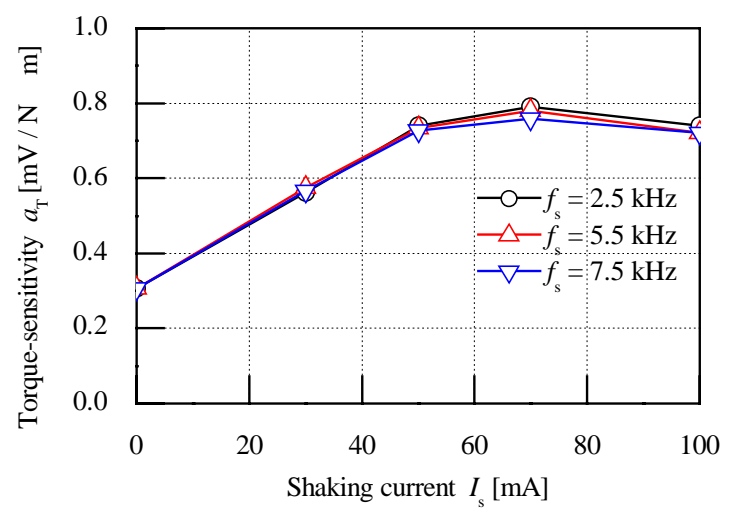

Fig. 8 Torque-sensitive characteristics vs. shaking current on superposition of shaking frequency $f_{\mathrm{s}} \neq n f_{\mathrm{e}}$

( $f_{\mathrm{e}}=1 \mathrm{kHz}, I_{\mathrm{e}}=30 \mathrm{~mA}, g=0.5 \mathrm{~mm}, \mathrm{~S} 25 \mathrm{C}$ shaft).

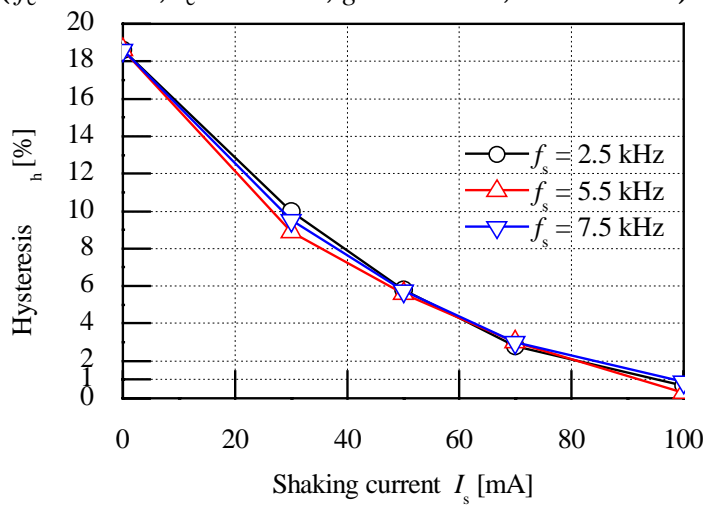

Fig. 9 Hysteresis characteristics vs. shaking aurrent on superposition of shaking frequency $f_{\mathrm{s}} \neq n f_{\mathrm{e}}$ ( $f_{\mathrm{e}}=1 \mathrm{kHz}, I_{\mathrm{e}}=30 \mathrm{~mA}, g=0.5 \mathrm{~mm}, \mathrm{~S} 25 \mathrm{C}$ shaft).

ここに, $v_{\mathrm{e}}$ : 厉振用波形の瞬時電圧 $[\mathrm{V}], V_{\mathrm{e}}$ : 厉振用波形の実効 電圧值 $[\mathrm{V}], f_{\mathrm{e}}$ : 厉振周波数 [Hz],$v_{\mathrm{s}}$ : シェイキング用波形の瞬時 電圧 $[\mathrm{V}], V_{\mathrm{s}}$ : シェイキング用波形の実効電圧值 $[\mathrm{V}], f_{\mathrm{s}}:$ シェイ キング周波数 $[\mathrm{Hz}]$

\section{2 シェイキング周波数を励振周波数の半整数倍とした時}

励振条件は，ヒステリシスが $18 \%$ ヒある励振周波数 $f_{\mathrm{e}}=1 \mathrm{kHz}$, 励振電流 $I_{\mathrm{e}}=30 \mathrm{~mA}$ に設定して, 重畳させるシェイキング周波数 $f_{\mathrm{s}}=2.5,5.5,7.5 \mathrm{kHz}$ と厉振周波数の半整数倍として加算した . こ れは, 励振用波形とシェイキング用波形の重畳波形を常に変化さ せるためである .

Fig. 8 に , シェイキング周波数 $f_{\mathrm{s}} \neq n f_{\mathrm{e}}$ 重畳時におけるトルク感 度特性を示した.いずれのシェイキング周波数 $f_{\mathrm{s}}$ においても，シェ イキング電流 $I_{\mathrm{s}}$ を増加するとトルク感度は飽和傾向を示しながら 上昇することが分かった . シェイキンク磁界を重畳させることで, シャフトの磁化特性における透磁率を高め, かつ保磁力を減少さ せる ${ }^{9)}$.従って , シェイキング電流力低い範囲ではトルク感度は増 加したが , シェイキング電流を $100 \mathrm{~mA}$ まて増加させることで， シャフトの飽和領域まて磁界か印加され透磁率が咸少したため卜 ルク感度が減少したと考えられる。

Fig. 9 に , シェイキング周波数 $f_{\mathrm{s}} \neq n f_{\mathrm{e}}$ 重畳時におけるヒステリ シス特性を示した.いずれのシェイキング周波数 $f_{\mathrm{s}}$ においても , シ エイキング電流 $I_{\mathrm{s}}$ を印加する前 $\left(I_{\mathrm{s}}=0 \mathrm{~mA}\right)$ から $100 \mathrm{~mA}$ まて増 加すると, ヒステリシスは $18 \%$ 加 $1 \%$ 以下に低减した 。 


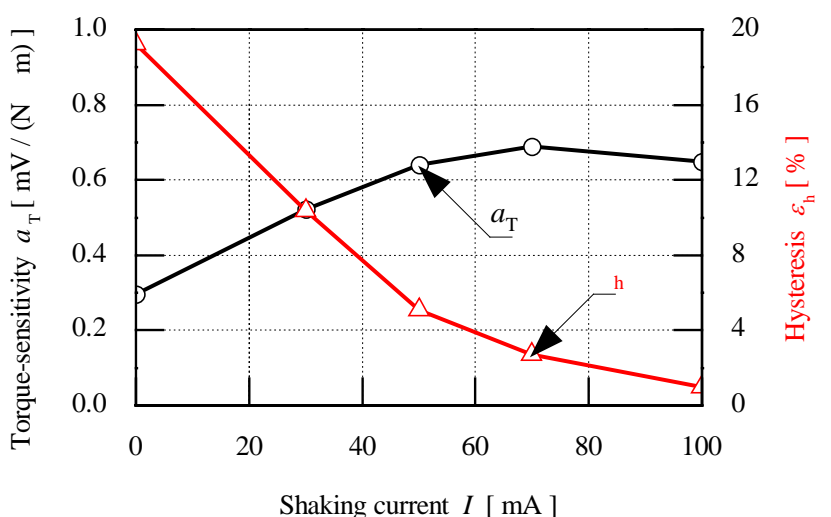

Fig. 10 Torque-sensitive and hysteresis charaderistics vs. shaking current on superposition of the shaking frequency $f_{\mathrm{s}}=4 \mathrm{kHz} \quad\left(f_{\mathrm{e}}=1 \mathrm{kHz}, I_{\mathrm{e}}=30 \mathrm{~mA}, f_{\mathrm{s}}=4 \mathrm{kHz}, g=0.5 \mathrm{~mm}\right.$, S25C shaft).

\section{3 シェイキング周波数を励振周波数の整数倍とした時}

励振条件は, 厉振周波数 $\mathrm{f}_{\mathrm{e}}=1 \mathrm{kHz}$, 厉振電流 $I_{\mathrm{e}}=30 \mathrm{~mA}$ に設定 して, 重畳させるシェイキング周波数 $f_{\mathrm{s}}=4,5 \mathrm{kHz}$ と厉振周波数 の整数倍 (偶・奇数倍) に設定して加算した .

Fig. 10 に , シェイキング周波数 $f_{\mathrm{s}}=4 \mathrm{kHz}$ 重畳時におけるトル ク感度特性，ヒステリシス特性を示した .ヒステリシス特性にお いて ,シェイキング電流 $I_{\mathrm{s}}$ を印加する前 $\left(I_{\mathrm{s}}=0 \mathrm{~mA}\right)$ から $100 \mathrm{~mA}$ まて増加すると，ヒステリシスは $18 \%$ \%から 1 \%以下に低減した . トルク感度特性において , シェイキング電流を増加すると , 飽和 傾向を示しながら上昇することが分かった 。

Fig. 11 に , シェイキング周波数 $f_{\mathrm{s}}=5 \mathrm{kHz}$ 重畳時におけるトル ク感度特性 , ヒステリシス特性を示した .ヒステリシス特性にお いて , シェイキング電流 $I_{\mathrm{s}}$ を $100 \mathrm{~mA}$ まて増加すると，ヒステリ シスは $18 \%$ \%か 1 \%以下に低減した，トルク感度特性において， シェイキング電流を増加すると，トルク感度はシェイキング電流 にほぼ比例して上昇した 。

PSD を通過することで, Fig. 7より, シェイキング周波数力淤 振周波数の偶数倍であるとき, シェイキング用波形の振幅は, 励 振用波形との初期位相角とは無関係に加算されLPF て平均化され るため, 直流成分はゼ口になる .一方 , 奇数倍であるとき , 厉振 用波形との初期位相角が0。であれば，シェイキング用波形の半 波周期分の振幅がLPF で平均化されるため, 出力電圧を強調する 結果となり, トルク感度が上昇した．

これに対して シェイキング用波形か渏数倍で初期位相角 $90^{\circ}$ の場合 , シェイキング用波形の半波周期分の振幅の重みは存在せ ず，トルク感度は数\%しか上昇しなかった .

また , 消費電力における磁気シェイキング法の効果として , 励 振電流 $I_{\mathrm{e}}=30 \mathrm{~mA}$, シェイキング電流 $I_{\mathrm{s}}=80 \mathrm{~mA}$ を加え , 約 $1 \mathrm{~W}$ までの低消費電力領域において，ヒステリシス特性は単一励振と ほぼ変わらなかった . トルク感度特性においては, シェイキング 周波数力渏数倍て初期位相角が 0 ○ 0 時, 単一励振よりトルク感 度が10\%程度増加した . 発熱においては, コイル系およひ軸に影 響を及ぼす程の問題はなかつた .

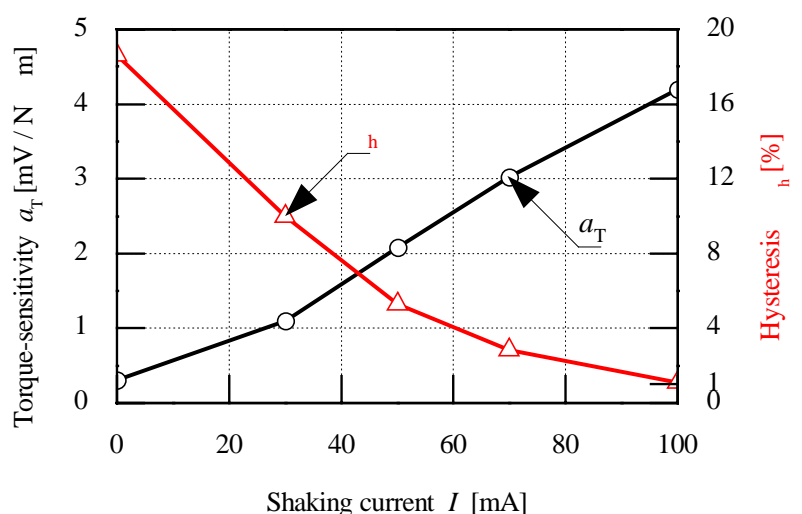

Fig. 11 Torque-sensitive and hysteresis characteristics vs. shaking current on superposition of the shaking frequency $f_{\mathrm{s}}=5 \mathrm{kHz} \quad\left(f_{\mathrm{e}}=1 \mathrm{kHz}, I_{\mathrm{e}}=30 \mathrm{~mA}, f_{\mathrm{s}}=5 \mathrm{kHz}, g=0.5 \mathrm{~mm}\right.$, S25C shaft).

\section{5. おわりに}

本論文では, トルクに対するヒステリシスを低減するために， 励振磁界とは異なる周波数の交流磁界を重畳する, 磁気シェイキ ング法を適用し検討を行った . 以下に , 本論文て明らかになった ことを示す.

(1) シェイキング周波数を厉振周波数の半整数倍とした時, シェ イキンク磁界の振幅を大きくすることで , ヒステリシスを $1 \%$ 以下に低減でき, トルク感度は飽和傾向を示すことが分 かった .

(2) シェイキング周波数を厉振周波数の偶数倍とした時 , シェイ キンク磁界の振幅を大きくすることで，ヒステリシスを $1 \%$ 以下に低減でき，トルク感度は飽和傾向を示した。

（3）シェイキング周波数を励振周波数の奇数倍とした時 , シェイ キンク磁界の振幅を大きくすることで，ヒステリシスを $1 \%$ 以下に低減でき, トルク感度はシェイキンク磁界にほほ比例 して上昇することが分かった .PSD を通過することで, 励振 用波形との初期位相角が0。であれば,シェイキング用波形 の半波周期分の振幅がLPF て平均化されるため,出力電圧を 強調する結果となり，トルク感度が上昇した。

\section{References}

1) I. Sasada, S. Uramoto, and K. Harada: J. Magn. Soc. J pn., 10, 379 (1986).

2) H. Wakiwka, M. Mitamura, S. Yamada, Y. Ito, T. Kamada, and M. Horiuchi: J. Magn. Soc. J pn., 25, 963-966 (2001).

3) H. Wakiwaka, M. Mitamura: Sensors and Actuators , A91, 103-106 (2001).

4) E. Nagano, I. Sasada, and K. Harada: J . Magn. Soc. J pn., 15, 485-488 (1991).

5) I. Sasada, E. Nagano, and K. Harada: J. Appl. Phys., 69, 4919-4921 (1991).

6) H. Wakiwaka, M. Mitamura, K. Banno: Technical Meeting on Magn. IEEJ ., MAG-99-68., 37-39 (1999).

7) H. Wakiwaka, M. Kobayashi, and H. Yamada: J. Magn. Soc. J pn., 14, 387 (1990).

8) H. Wakiwaka, M. Mitamura, Y. Ito, M. Horiuchi, T. Kamada: Electromagnetics and Dynamics, 224, 319-322 (2001).

9) V. Kelha, R. Peltonen, and Borje Rantala: IEEE Trans. Magn., MAG-16, 575-578 (1980).

2004 年 10 月 6 日受理 , 2005 年 2 月 8 日採録 